\title{
Early and late outcome of cardiac surgery in dialysis- dependent patients: Single-center experience with 245 consecutive patients
}

Parwis B. Rahmanian, MD, ${ }^{a}$ David H. Adams, MD, ${ }^{a}$ Javier G. Castillo, MD, ${ }^{\text {a }}$ Joseph Vassalotti, MD, ${ }^{\text {b }}$ and Farzan Filsoufi, MDa

From the Department of Cardiothoracic Surgery $^{\mathrm{a}}$ and the Division of Nephrology, Mount Sinai School of Medicine, New York, NY.

Received for publication June 19, 2007; revisions received Aug 22, 2007; accepted for publication Sept 12, 2007.

Address for reprints: Farzan Filsoufi, MD, Department of Cardiothoracic Surgery, Mount Sinai School of Medicine, 1190 Fifth Ave, Box 1028, New York, NY 10029 (E-mail: Farzan.filsoufi@mountsinai.org).

J Thorac Cardiovasc Surg 2008;135:915-22 0022-5223/\$34.00

Copyright (C) 2008 by The American Association for Thoracic Surgery

doi:10.1016/j.jtcvs.2007.09.027
Objective: Previous studies on outcome of cardiac surgery and its predictors in patients with preoperative kidney failure requiring dialysis have included small numbers of patients with limited follow-up. In addition, predictors of long-term outcome are not well characterized.

Methods: This is a retrospective analysis of prospectively collected data for 6694 patients, including $245(3.7 \%)$ patients with end-stage kidney failure requiring dialysis who underwent cardiac surgery between January 1998 and September 2006. Potential predictors of hospital mortality, complications, and late survival were retrospectively analyzed by using multivariate regression models.

Results: Patients with end-stage kidney failure requiring dialysis had a 3.9-times higher hospital mortality rate compared with other cardiac surgery patients $(12.7 \%$ vs $3.6 \%, P<.001)$. Patients with end-stage kidney failure requiring dialysis were younger but presented with more comorbidities and more severe cardiac disease than the control group. After adjusting for potential confounding factors, end-stage kidney failure requiring dialysis was identified as a predictor of hospital mortality (odds ratio, $3.1 ; P<.001$ ). Patients with end-stage kidney failure requiring dialysis also had an increased risk of postoperative sepsis (odds ratio, 2.7; $P<.001$ ) and respiratory failure (odds ratio, $2.0 ; P<.001$ ). Peripheral vascular disease was an independent predictor of hospital mortality in patients with end-stage kidney failure requiring dialysis (odds ratio, 2.5; $P=.001$ ). Long-term survival was significantly decreased in patients with end-stage kidney failure requiring dialysis compared with that seen in the control group (1-year and 5-year survival: $72.3 \% \pm 3.3 \%$ and $39.0 \% \pm 4.5 \%$ vs $94.2 \% \pm 0.3 \%$ and $83.2 \% \pm 0.6 \%, P<.001)$. Peripheral vascular disease (odds ratio, $2.69 ; P=.008$ ) and previous stroke (odds ratio, $4.37 ; P<.001$ ) were independent risk factors of late mortality in the subgroup of patients with endstage kidney failure requiring dialysis.

Conclusions: Preoperative renal failure requiring dialysis is associated with a significant increase in hospital mortality, postoperative sepsis, and respiratory failure in patients undergoing cardiac surgery. In these patients long-term survival is particularly reduced in the presence of advanced atherosclerotic disease.

$\mathrm{E}$ nd-stage kidney failure requiring dialysis (ESRD) represents a major public health problem in the United States related to an aging population and an increasing incidence of certain risk factors, such as diabetes mellitus, hypertension, and atherosclerotic disease. ${ }^{1}$ Patients with ESRD are at higher risk for the development of cardiovascular diseases, including coronary artery disease and valvular heart disease. ${ }^{2}$ An improved survival of patients with ESRD in recent years has led to an increased referral of dialysis patients for cardiac surgery. The postoperative outcomes after cardiac surgery are worse compared with those of patients without ESRD. ${ }^{3}$ However, most previous studies are limited by small sample size and unable 


\author{
Abbreviations and Acronyms \\ $\mathrm{CABG}=$ coronary artery bypass grafting \\ $\mathrm{CI}=$ confidence interval \\ $\mathrm{CPB}=$ cardiopulmonary bypass \\ $\mathrm{ESRD}=$ end-stage kidney failure requiring dialysis \\ $\mathrm{OR}=$ odds ratio \\ PVD = peripheral vascular disease
}

to identify independent predictors of outcome. In addition, they have primarily focused on early surgical results with limited follow-up. In this study we report our clinical experience in a large contemporary series of patients with ESRD who underwent cardiac surgery at a single institution. We sought to determine surgical outcomes and predictors of early and late mortality.

\section{Materials and Methods}

We retrospectively analyzed a series of 6940 consecutive patients undergoing cardiovascular surgery at the Mount Sinai Medical Center between January 1998 and September 2006. Patients undergoing cardiac transplantation and ventricular assist device implantation $(n=246)$ were excluded from this study. The remaining 6694 patients were included in the statistical analysis. Two hundred forty-five patients with ESRD constituted the study group, whereas 6449 patients served as the control group. Patients were further divided into 4 groups according to the surgical procedure (isolated valve procedures, $\mathrm{n}=1454$ [22\%]; coronary artery bypass grafting [CABG], $\mathrm{n}=2916$ [43\%]; combined valve/CABG procedures, $\mathrm{n}=1071$ [16\%]; and aortic procedures, $\mathrm{n}=1253$ [19\%]). The protocol was approved by the institutional review board and complies with the Health Insurance Portability and Accountability Act and the ethical guidelines of the 1975 declaration of Helsinki, as revised in 2000. The approval included a waiver of informed consent.

\section{Data Collection}

Clinical variables were prospectively entered into the New York State Department of Health (State Cardiac Advisory Committee) data registry. The New York State Department of Health data registry represents a mandatory, verified, peer-reviewed data collection system including all adult cardiac surgery procedures in the state of New York and records and analyzes data in a strictly supervised and widely reported fashion. ${ }^{4}$ Patient demographics and risk factors, operative information, and postoperative outcome data were retrospectively analyzed. Additional information was obtained from patient charts when necessary. Appendix 1 shows preoperative variables and their definitions. In addition, the logistic EuroSCORE was used for risk stratification. ${ }^{5}$ The EuroSCORE is a risk-stratification system using multiple preoperative risk factors to predict operative mortality. Patients were stratified according to EuroSCORE as follows: EuroSCORE of $9 \%$ or less, low to moderate risk; EuroSCORE of greater than $9 \%$ to $25 \%$, high risk; and EuroSCORE of greater than $25 \%$, very high risk. ${ }^{5}$ Outcome measures in this study included hospital mortality, major postoperative complications, and length of stay in the hospital (Appendix 1). Follow-up survival information was obtained by cross-matching the patient's social security number with the Web-based social security death index.

\section{Operative Procedures and Perioperative Management}

Hemodialysis was performed in all patients in the ESRD group 12 to 24 hours before surgical intervention. All procedures were performed by using standard anesthetic and surgical techniques. A small skin incision and a full or partial sternotomy were performed in patients undergoing valve, $\mathrm{CABG}$, or aortic surgery procedures involving the ascending aorta or the aortic arch. Descending thoracic aortic surgery was performed through a left thoracotomy approach. After systemic heparinization, cardiopulmonary bypass (CPB) was instituted between the ascending aorta and either the right atrium by using a 2 -stage cannula or both venae cavae. During $\mathrm{CPB}$, a minimum flow of $2.5 \mathrm{~L} \cdot \mathrm{min}^{-1} \cdot \mathrm{m}^{-2}$ and mean arterial pressures of approximately $60 \mathrm{~mm} \mathrm{Hg}(70 \mathrm{~mm} \mathrm{Hg}$ in patients with peripheral vascular disease [PVD]) were maintained. Cardioplegia with high-potassium cold blood was administered in an antegrade fashion, a retrograde fashion, or both for myocardial protection. In patients undergoing valve surgery, further myocardial protection was obtained with mild-to-moderate systemic cooling $\left(28^{\circ} \mathrm{C}-30^{\circ} \mathrm{C}\right)$. Procedures involving the aortic arch were performed during deep hypothermic circulatory arrest. After the completion of $\mathrm{CPB}$, protamine was administered based on the heparin level. Intraoperative variables used in this study are reported in Appendix 1. Patients with ESRD underwent postoperative hemodialysis routinely on the second day after surgical intervention or earlier if volume overload or hyperkalemia was present.

\section{Statistical Analysis}

Normally distributed continuous variables are presented as means \pm standard deviations and otherwise as medians and interquartile ranges. Categorical variables are shown as the percentage of the sample. The $\chi^{2}$ test was used to evaluate potential confounders of the relationship between ESRD and hospital mortality and morbidities in the entire patient population. Stepwise multivariate logistic regression was then performed to assess the influence of ESRD as an independent risk factor for hospital mortality and postoperative morbidities. ${ }^{6}$ The potential confounders included age, sex, obesity (body mass index $>30 \mathrm{~kg} / \mathrm{m}^{2}$ ), ejection fraction, congestive heart failure, previous cardiac procedure, history of diabetes mellitus, hypertension, history of myocardial infarction, acute myocardial infarction, chronic obstructive pulmonary disease, PVD, hemodynamic instability, and type of operative procedure (isolated CABG, valvular surgery, combined valve/CABG, and aortic procedures). Long-term survival was analyzed by using Kaplan-Meier survival curves. Differences in patient characteristics were controlled with Cox proportional hazard analysis. The statistical analyses were performed with SPSS 15 (SPSS, Inc, Chicago, Ill).

\section{Results \\ Demographic Data}

A total of 6694 patients were included in this study. Hemodialysis-dependent renal failure was present in 245 (3.7\%) patients. During the study period, the prevalence of patients with ESRD increased (3.0\% in 1998 to $5.1 \%$ in 2006, $P=$ .008). There were important differences in preoperative 
characteristics between patients with and without ESRD (Table 1). Patients with ESRD were younger $(P<.001)$ and were more likely to present with hypertension $(P=$ $.001)$, diabetes mellitus $(P<.001)$, PVD $(P<.001)$, prior cerebrovascular accident $(P<.001)$, congestive heart failure $(P<.001)$, and an ejection fraction of $30 \%$ or less $(P<.001)$ when compared with the control group. These patients also presented significantly more often with acute endocarditis $(P<.001)$ and hemodynamic instability on admission $(P<.001)$. The mean predicted mortality by means of EuroSCORE was significantly higher in the study group $(18.5 \% \pm$ $17.5 \%)$ compared with that seen in the control group (11.6\% $\pm 13.3 \%, P<.001)$. Finally, patients with ESRD were more likely to undergo isolated single or multiple valve procedures $(P=.001)$ and less likely to undergo aortic procedures $(P=.017)$ compared with the control population. The most common valve operation in patients with ESRD was aortic valve replacement, followed by mitral valve procedures.

\section{Hospital Mortality}

The overall hospital mortality was 3.9\% (262 patients). In patients with ESRD, univariate analysis showed a significantly increased hospital mortality $(\mathrm{n}=31[12.7 \%])$ compared with that seen in the control group $(\mathrm{n}=231$ [3.6\%], $P<.001$, Table 2). When patients were stratified by EuroSCORE, the observed mortality rate was higher for patients with ESRD in all 3 predicted risk groups compared with the control group $(P<.001$, Figure 1). When patients with ESRD were stratified by procedure, it appeared that the highest mortality rate occurred in patients undergoing single/multiple valve procedures $(17.1 \%)$, followed by combined valve/ CABG (12.8\%), isolated CABG (10.3\%), and aortic (9.1\%) procedures (Figure 2).

The estimated odds of ESRD hospital mortality, relative to the control group, was 3.9 (95\% confidence interval [CI], 2.6-5.8; $P<.001)$ ). In a stepwise, multivariate, logistic regression analysis including the entire patient population, ESRD remained a statistically significant independent factor predicting the risk of hospital mortality (relative odds ratio [OR], 3.1; 95\% CI, 2.0-5.0; $P<.001)$. Multivariate analysis also revealed hemodynamic instability (OR, 4.1; 95\% CI, 2.6-6.4; $P<.001)$, acute myocardial infarction (OR, 5.0; 95\% CI, 2.5-10.1; $P<.001$ ), PVD (OR, 2.8; 95\% CI, 2.1-3.9; $P<.001)$, reoperation (OR, 1.7 ; 95\% CI, 1.3-2.4; $P=.001)$, endocarditis (OR, 2.5; 95\% CI, 1.4-4.4; $P=.002)$, ejection fraction of $30 \%$ or less (OR, $1.8 ; 95 \%$ CI, 1.2-2.6; $P=.002)$, age greater than 70 years (OR, 1.4; 95\% CI, 1.1-1.9; $P=.013$ ), female sex (OR, $1.4 ; 95 \% \mathrm{CI}$, $1.1-1.8 ; P=.019)$, congestive heart failure (OR, 1.6; 95\% CI, 1.2-2.2; $P=.002$ ), and an operation involving the thoracic aorta (OR, 2.0; 95\% CI, 1.4-2.8; $P<.001)$ as independent predictors of hospital mortality. Because of the relatively large sample size, we also performed a second
TABLE 1. Patient demographic and risk factors

\begin{tabular}{|c|c|c|c|}
\hline Characteristic & $\begin{array}{l}\text { Control group } \\
(n=6449)\end{array}$ & $\begin{array}{l}\text { Dialysis group } \\
\quad(n=245)\end{array}$ & $P$ value \\
\hline Female sex & $2423(37.6 \%)$ & $91(37.1 \%)$ & .475 \\
\hline Age (year) & $63.9 \pm 13.8$ & $61 \pm 13.2$ & .000 \\
\hline Age $>70 y$ & $2327(36.1 \%)$ & $62(25.3 \%)$ & .001 \\
\hline $\begin{array}{l}\text { Body mass } \\
\quad \text { index }\left(\mathrm{kg} / \mathrm{m}^{2}\right)\end{array}$ & $26.8 \pm 6.2$ & $26.4 \pm 5.3$ & .605 \\
\hline $\begin{array}{l}\text { Body mass } \\
\quad \text { index }>30 \mathrm{~kg} / \mathrm{m}^{2}\end{array}$ & $1395(21.6 \%)$ & $48(19.6 \%)$ & .250 \\
\hline Ejection fraction (\%) & $47.6 \pm 14.2$ & $43.8 \pm 14.9$ & .000 \\
\hline Ejection fraction $<30 \%$ & $719(11.1 \%)$ & $40(16.3 \%)$ & .010 \\
\hline Hypertension & $3016(46.8 \%)$ & $140(57.1 \%)$ & .001 \\
\hline Diabetes & $1548(24.0 \%)$ & $104(42.4 \%)$ & .000 \\
\hline $\begin{array}{l}\text { Peripheral vascular } \\
\text { disease }\end{array}$ & $776(12.0 \%)$ & $66(26.9 \%)$ & .000 \\
\hline Cerebrovascular accident & $490(7.6 \%)$ & $38(15.5 \%)$ & .000 \\
\hline $\begin{array}{l}\text { Chronic obstructive } \\
\text { pulmonary disease }\end{array}$ & $462(7.2 \%)$ & $14(5.7 \%)$ & .234 \\
\hline Prior myocardial infarction & $1938(30.1 \%)$ & $81(33.1 \%)$ & .174 \\
\hline $\begin{array}{l}\text { Acute myocardial } \\
\text { infarction }\end{array}$ & $77(1.2 \%)$ & $4(1.6 \%)$ & .345 \\
\hline Congestive heart failure & $1888(29.3 \%)$ & $129(52.7 \%)$ & .000 \\
\hline Hemodynamic instability & $193(3.0 \%)$ & $22(9.0 \%)$ & .000 \\
\hline Reoperation & $958(14.9 \%)$ & $36(14.7 \%)$ & .517 \\
\hline Endocarditis & $128(2.0 \%)$ & $28(11.4 \%)$ & .000 \\
\hline EuroSCORE & $11.6 \% \pm 13.3 \%$ & $18.0 \% \pm 17.5 \%$ & .000 \\
\hline Low-moderate risk $(<9 \%)$ & $3762(58.3 \%)$ & $59(24.1 \%)$ & .000 \\
\hline High risk $(9 \%-25 \%)$ & $1720(26.7 \%)$ & $93(38.0 \%)$ & .000 \\
\hline Very high risk (>25\%) & $967(15.0 \%)$ & $93(38.0 \%)$ & .000 \\
\hline \multicolumn{4}{|l|}{ Procedures } \\
\hline Isolated valve procedures & $1378(21.4 \%)$ & $76(31.0 \%)$ & .001 \\
\hline Isolated CABG procedures & $2819(43.7 \%)$ & $97(39.6 \%)$ & .113 \\
\hline $\begin{array}{l}\text { Combined valve/CABG and } \\
\text { other procedures }\end{array}$ & $1032(16.0 \%)$ & $39(15.9 \%)$ & .529 \\
\hline Aortic procedures & $1220(18.9 \%)$ & $33(13.5 \%)$ & .017 \\
\hline
\end{tabular}

$C A B G$, Coronary artery bypass grafting.

analysis of independent predictors of hospital mortality in patients with ESRD. This analysis revealed only PVD as an independent predictor of hospital mortality (OR, 2.5; $95 \%$ CI, 1.1-5.7; $P=.001)$.

\section{Morbidity}

In univariate analysis patients with ESRD presented significantly more often with respiratory failure $(P<.001)$, sepsis $(P<.001)$, and gastrointestinal complications $(P<.001)$ compared with the control group. Variables associated with postoperative morbidities in univariate analysis were introduced into stepwise logistic regression analysis. In this multivariate analysis the correlation between ESRD and the occurrence of respiratory failure and sepsis remained statistically significant. However, the correlation between dialysisdependent renal failure and gastrointestinal complications disappeared (Table 3). The mean length of stay in the hospital 
TABLE 2. Mortality and Morbidity

\begin{tabular}{lccc}
\hline \multicolumn{1}{c}{ Complication } & Control group & Dialysis group & \\
& $(\mathbf{n}=\mathbf{6 4 4 9 )}$ & $(\mathbf{n}=\mathbf{2 4 5})$ & $\boldsymbol{P}$ value \\
\hline In-hospital mortality & $231(3.6 \%)$ & $31(12.7 \%)$ & .000 \\
Renal failure & $139(2.2 \%)$ & - & \\
Respiratory failure & $617(9.6 \%)$ & $53(21.6 \%)$ & .000 \\
Sepsis & $188(2.9 \%)$ & $27(11.0 \%)$ & .000 \\
Gastrointestinal complications & $101(1.6 \%)$ & $10(4.1 \%)$ & .000 \\
Cerebrovascular accident & $160(2.5 \%)$ & $8(3.3 \%)$ & .273 \\
Sternal infection & $103(1.6 \%)$ & $6(2.4 \%)$ & .209 \\
Myocardial infarction & $39(0.6 \%)$ & $2(0.8 \%)$ & .446 \\
Reoperation for bleeding & $158(2.4 \%)$ & $4(1.6 \%)$ & .286 \\
LOS $\geq 7$ d & $3775(58.5 \%)$ & $189(77.1 \%)$ & .000 \\
\hline
\end{tabular}

LOS, Length of stay in hospital.

among surviving patients was $13 \pm 18$ days. The mean length of stay among patients with ESRD was $25 \pm 34$ days compared with $12 \pm 17$ days in the control group $(P<.001)$.

\section{Late Survival}

Follow-up survival information was available for $98 \%$ ( $\mathrm{n}=$ 6304/6432) of discharged patients. Among 214 surviving patients with ESRD, follow-up information was available for 212 patients. The overall mean follow-up was $3.9 \pm 2.5$ years, with $3.1 \pm 2.4$ years for patients with ESRD compared with $3.9 \pm 2.5$ years for control subjects $(P<.001)$. There were $973(15.1 \%)$ deaths during the total follow-up period of 22,697 patient-years. During follow-up, 94 (44\%) patients died in the ESRD group compared with 879 (14.1\%) deaths in the control group $(P<.001)$. Multivariate analysis revealed ESRD (OR, 5.6; 95\% CI, 4.0-7.9; $P<.001$ ) as an independent predictor of late mortality after cardiac surgery

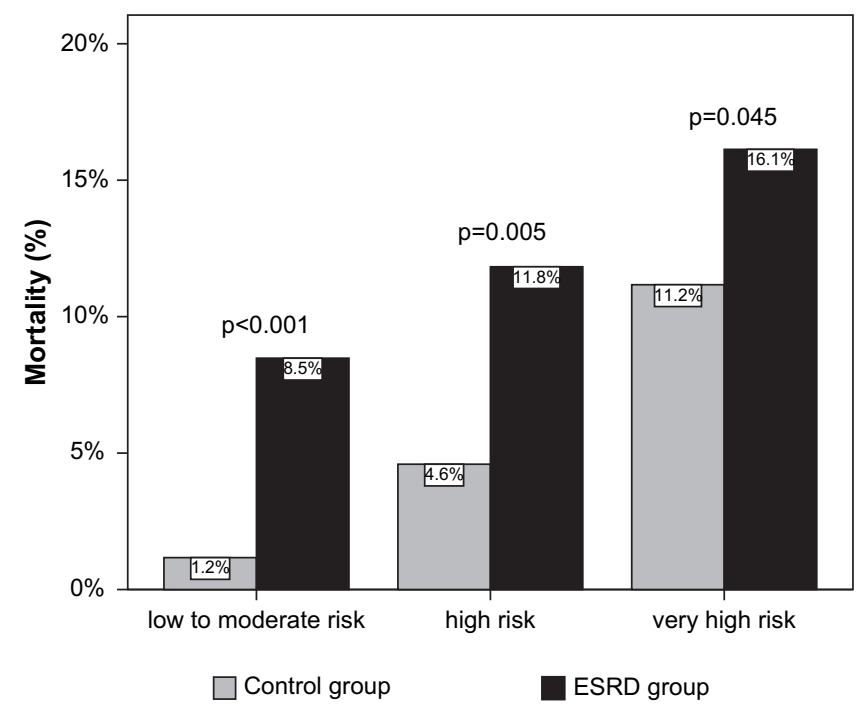

Figure 1. Crude mortality according to EuroSCORE group. ESDR, End-stage renal failure requiring dialysis.

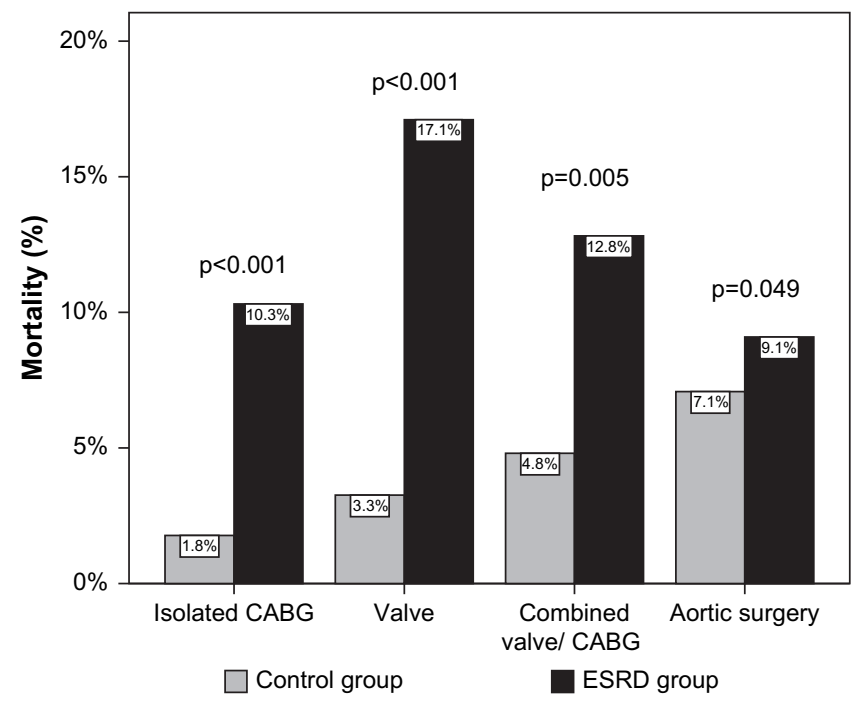

Figure 2. Crude mortality according to procedure. CABG, Coronary artery bypass grafting, ESDR, end-stage renal failure requiring dialysis.

(Table 3). Survival at 1 and 5 years was $72.3 \% \pm 3.3 \%$ and $39.0 \% \pm 4.5 \%$ in the ESRD group and $94.2 \% \pm 0.3 \%$ and $83.2 \% \pm 0.6 \%$ in the control group, respectively $(P<$ $.001)$. Figure 3 shows adjusted Kaplan-Meier survival curves for the entire patient population stratified by study and control group. In the subgroup of patients with ESRD, PVD (OR, 2.7; 95\% CI, 1.3-5.6; $P=.008$ ) and previous cerebrovascular accident (OR, 4.4; 95\% CI, 1.8-10.8; $P=.001)$ were independent predictors of late mortality. Three-year survival of patients with additional stroke or PVD was $14.1 \% \pm$ $7.2 \%$ and $32.8 \% \pm 7.8 \%$, respectively. Figure 4 shows the effect of PVD and previous stroke on long-term survival in patients with ESRD after cardiac surgery.

TABLE 3. The effect of dialysis of hospital mortality and morbidity in multivariate analysis

\begin{tabular}{lccc}
\hline & OR & 95\% CI & $\boldsymbol{P}$ value \\
\hline Death & 3.12 & $1.96-4.97$ & .000 \\
Sepsis & 2.65 & $1.64-4.28$ & .000 \\
Respiratory failure & 1.96 & $1.38-2.80$ & .000 \\
Gastrointestinal & 1.64 & $0.79-3.38$ & .183 \\
$\quad$ complication & & & \\
Bleeding & 0.62 & $0.23-1.73$ & .364 \\
Myocardial infarction & 1.22 & $0.28-5.25$ & .788 \\
Sternal infection & 0.88 & $0.37-2.12$ & .783 \\
Stroke & 1.07 & $0.51-2.27$ & .856 \\
Late death & 5.64 & $4.03-7.88$ & .000 \\
\hline
\end{tabular}

OR, Odds ratio; $95 \% \mathrm{Cl}, 95 \%$ confidence interval. 

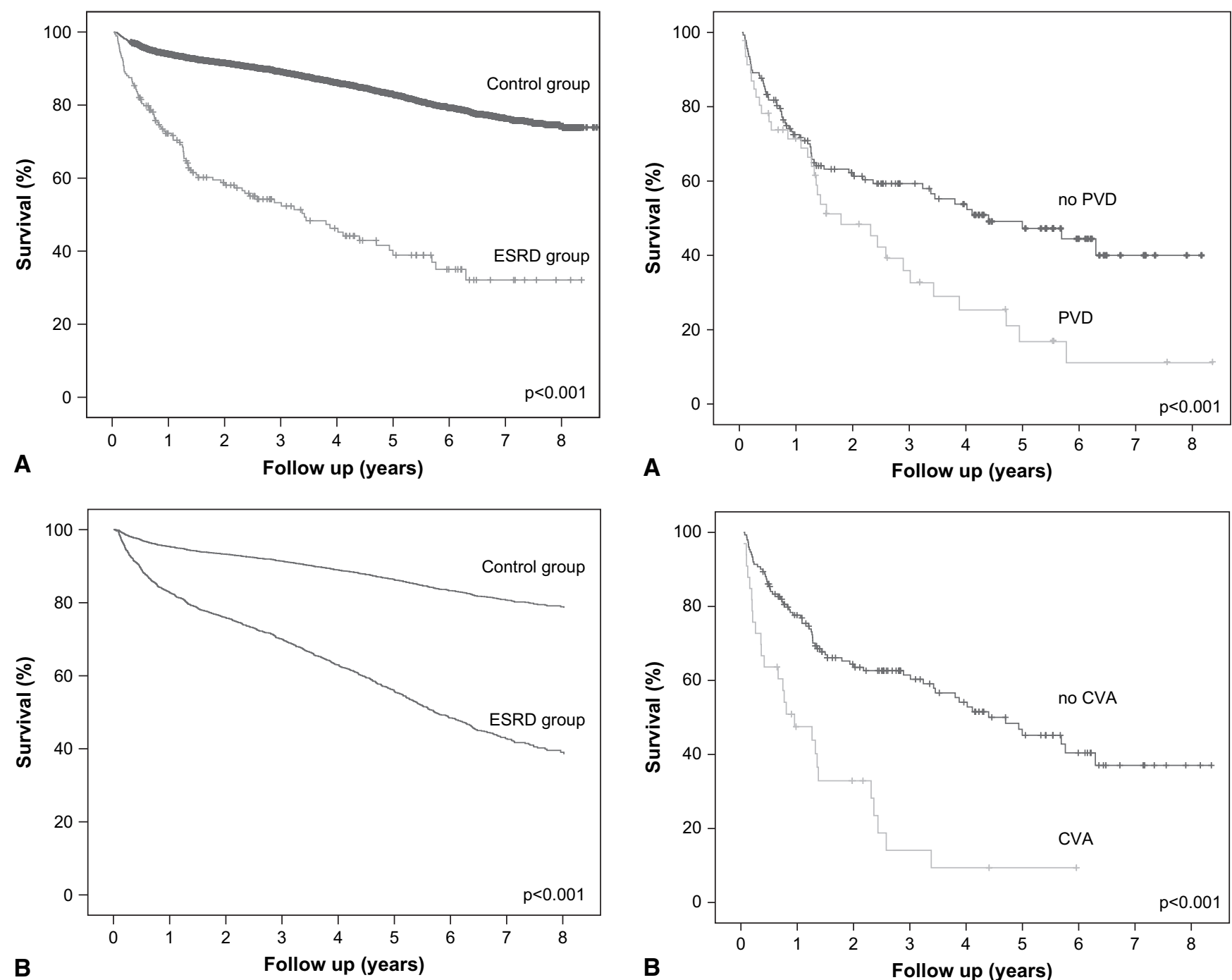

Figure 3. Nonadjusted (A) and adjusted (B) survival curves for patients with and without end-stage renal failure requiring dialysis (ESDR).

\section{Discussion}

\section{Incidence}

The prevalence of chronic renal disease among the population of the United States is steadily increasing, with more than 472,000 patients with end-stage renal failure in 2004, a number that is expected to double by $2010 .^{7}$ Cardiovascular disease is frequently associated with ESRD and is the most common cause of death in this patient population. ${ }^{8}$ Liu and colleagues $^{9}$ reported a multicenter series including more than 15,000 patients who underwent isolated CABG between 1992 and 1997 and reported an incidence of $1.8 \%(n=279)$ patients with ESRD. Ferguson and associates ${ }^{10}$ analyzed the Society of Thoracic Surgeons national database entries of

patients who underwent CABG between 1990 and 1999 and reported an increasing rate of patients with renal failure (creatinine value of $>2 \mathrm{mg} / \mathrm{dL}$ or dialysis), from $3.0 \%$ in 1990 to $4.6 \%$ in 1999 . Similarly, in our study we observed an increase in the prevalence of patients with ESRD during the study period $3.0 \%$ in 1998 and $5.1 \%$ in $2006, P=$ .008). The demographic profile of patients with ESRD was similar to that reported in previous studies. ${ }^{9,11}$ These patients represent a challenging population with high comorbidity, such as peripheral and cerebrovascular diseases, hypertension, and diabetes. Accordingly, the predicted operative mortality determined by means of EuroSCORE was significantly higher compared with that in the control group.

Figure 4. Impact of peripheral vascular disease (PVD)(A) and cerebrovascular accident (CVA)(B) on long-term survival in dialysisdependent patients. 


\section{Mortality}

Previous studies have identified ESRD as a major risk factor for postoperative morbidity and mortality. In 2000 Horst and coworkers ${ }^{12}$ published a review of the literature including 20 studies with a total of 863 dialysis-dependent patients who underwent all types of cardiac procedures. In this review the overall operative mortality was $12.5 \%$. In their multicenter study among patients undergoing CABG from northern New England, Liu and colleagues ${ }^{9}$ reported a 3-times higher adjusted mortality rate in dialysis-dependent patients (9.6\%) compared with those with normal renal function (3.1\%). Our experience confirmed these findings: the adjusted risk of hospital mortality was more than 3-times higher in patients with ESRD. Hospital mortality rate was increased regardless of the underlying procedure. The highest mortality rate, however, was observed in patients undergoing valvular surgery and combined valve/CABG procedures. This finding supports 2 small previous studies that focused primarily on operative mortality in patients who underwent valve surgery. ${ }^{3,12}$ In these 2 studies crude mortality was 3- to 4-times higher in patients undergoing valvular surgery compared with values in those who underwent isolated CABG. One possible explanation for the poorer outcome in these patients is a delay in surgical intervention because of an underestimation of valvular heart disease. ${ }^{12}$ In patients with ESRD, typical presentations of valvular heart disease caused by volume overload, such as shortness of breath, effusions, and other symptoms of congestive heart failure, can be concealed by dialysis, making accurate diagnosis difficult. ${ }^{12,13}$ In addition, because of known high operative risk, some of these patients might be referred late for cardiac surgery with advanced valvular lesions, including extensive calcification and impaired left ventricular function. While performing multivariate analysis in the ESRD subgroup, we were able to identify PVD as a predictor of hospital mortality. Dialysis-dependent patients with PVD were 2.5-times more likely to experience hospital mortality compared with patients with ESRD without PVD. This is probably a manifestation of the extent of atherosclerotic disease in these patients affecting multiple organs. These findings suggest that earlier detection of cardiac disease, as well as other associated atherosclerotic diseases, might lead to an earlier referral and potentially improve operative outcome in this high-risk population.

\section{Morbidity}

A number of previous studies reported an association of ESRD with major postoperative complications, such as reoperation for bleeding and coagulation disorders, stroke, respiratory failure, mediastinitis, and sepsis. ${ }^{9,12,14}$ We identified ESRD as an independent predictor of respiratory failure (OR, $2.0 ; 95 \% \mathrm{CI}, 1.4-2.8 ; P<.001)$ and sepsis (OR, 2.7; 95\% CI, $1.6-4.3 ; P<.001)$. Gastrointestinal complications showed an association with ESRD in univariate analysis, but this association disappeared in multivariate analysis. The increased risk for perioperative infectious complications in patients with ESRD might be explained by an immune-compromised state caused by uremia, frequent dialysis, diabetes, or steroid therapy for autoimmune causes of renal failure. However, despite the increased risk of postoperative septic complications, we did not observe a significant difference in the rate of mediastinitis between patients undergoing dialysis and our general patient population. This might be explained by a large number of patients who underwent valvular or aortic surgery in our series, which usually carries a lower risk of postoperative mediastinitis compared with that of CABG. ${ }^{15}$

In contrast to previous studies, ${ }^{9,16}$ we were not able to show an association between ESRD and postoperative stroke (3.3\% in patients with ESRD vs $2.5 \%$ in the control group, $P=.273$ ). The risk of stroke in patients with dialysis undergoing cardiac surgery is related to the burden of atherosclerotic disease, which predisposes patients with ESRD to thrombembolic events and ischemic injury from low perfusion pressure during $\mathrm{CPB} .{ }^{16}$ Our finding of a relatively low stroke rate $(3.3 \%)$ in this patient population compared with previous reports (6\% to $7 \%$ ) is probably related to the fact that we routinely apply epiaortic scanning before manipulation and cannulation of the ascending aorta in all patients, use the axillary artery instead of the femoral artery as an inflow for arterial cannulation in patients undergoing complex aortic surgery, and perform off-pump procedures in patients undergoing $\mathrm{CABG}$ at risk. ${ }^{17}$ Another important adjunct is that we maintain high perfusion pressure $(>70 \mathrm{~mm} \mathrm{Hg})$ during CPB in all patients with PVD or patients older than 70 years.

In contrast to some previous studies, we did not observe an association between ESRD and postoperative bleeding complications. Previous studies have reported a rate of postoperative bleeding in the range of $3 \%$ to $11 \%$ and associated this event with platelet dysfunction and coagulation defects caused by uremia and mechanical alterations of blood cells during dialysis. ${ }^{18}$ Although this study was not designed to determine the cause of reduced postoperative bleeding, the low rate of bleeding complications might be explained by the use of antifibrinolytic agents, such as $\varepsilon$-aminocaproic acid during CPB. In addition, we currently perform a thromboelastogram in these patients at the completion of CPB, with a low threshold for the transfusion of platelets in patients with abnormal findings and clinical signs of bleeding.

\section{Long-term Survival}

Few data exist with respect to long-term survival of patients with ESRD after cardiac surgery. In their review of the literature, Frenken and Krian ${ }^{3}$ were able to identify 5 case series with a total of 97 patients and reported a 5-year survival between $39 \%$ and $67 \%$. In the subgroup of patients undergoing valve procedures, the 5-year survival was only $39 \%$. Franga and coworkers, ${ }^{19}$ in their series of 44 patients, reported a 3 -year and 5-year survival of $64 \%$ and $32 \%$, respectively. Finally, Jault and colleagues ${ }^{20}$ followed 99 patients who 
underwent cardiac surgery between 1980 and 1998 and observed a survival of $47 \%$ at 6 years. In our series of 214 discharged patients, we observed 1-year, 3-year, and 5 -year survivals of $72.3 \% \pm 3.3 \%, 53.3 \% \pm 4.0 \%$, and $39.0 \% \pm 4.5 \%$ respectively. Late survival was not different when patients were stratified by underlying procedure. The importance of PVD and history of stroke for the outcome of patients with ESRD after cardiac surgery has not previously been demonstrated. In our study previous stroke and PVD were strong independent predictors of late mortality. Three-year survival was $14.1 \% \pm 7.2 \%$ and $32.8 \% \pm$ $7.8 \%$ for patients with previous stroke and PVD, respectively. These observations were confirmed when patients were stratified by predicted mortality by using EuroSCORE. These findings confirm that end-stage renal failure and associated atherosclerotic disease negatively affect late outcome after cardiac surgery. Therefore systematic preoperative work-up for detection of coexisting atherosclerotic disease is crucial to optimize patient selection to improve early and late outcome of patients with ESRD undergoing cardiac surgery.

\section{Limitations}

Despite the fact that all data were collected prospectively, this is a retrospective observational study, and therefore any conclusions are limited in their application. This study analyzes only patients with ESRD who were considered suitable by referring nephrologists and cardiologists to undergo cardiac operations. We do not have information about the number of patients with ESRD and cardiovascular diseases requiring surgical intervention who were considered to be too high risk by their primary care physician to undergo an invasive surgical procedure during the same time period. Although we report one of the largest series published in the literature, the validation of independent predictors observed in our study requires clinical series with greater numbers of patients with ESRD undergoing cardiac surgery. Finally, clinical outcome analysis focused on postoperative mortality and morbidity, and we were not able to provide information on late complications, quality of life, and cause of death after discharge.

\section{References}

1. Xue JL, Ma JZ, Louis TA, Collins AJ. Forecast of the number of patients with end-stage renal disease in the United States to the year 2010. J Am Soc Nephrol. 2001;12:2753-8.

2. Foley RN, Parfrey PS, Sarnak MJ. Clinical epidemiology of cardiovascular disease in chronic renal disease. Am J Kidney Dis. 1998;32(suppl 3):S112-9.
3. Frenken M, Krian A. Cardiovascular operations in patients with dialysisdependent renal failure. Ann Thorac Surg. 1999;68:887-93.

4. Adult Cardiac Surgery in New York State 2001-2003. Available at: http://www.nyhealth.gov/nysdoh/heart/pdf/2001-2003_cabg.pdf. Accessed April 15, 2007.

5. Nashef SA, Roques F, Michel P, Gauducheau E, Lemeshow S, Salamon R. European system for cardiac operative risk evaluation (EuroSCORE). Eur J Cardiothorac Surg. 1999;16:9-13.

6. Hosmer DW, Lemeshow S. Applied logistic regression. New York: Wiley; 1989.

7. US Renal Data System. USRDS 2006 Annual Data Report: atlas of end-stage renal disease in the united states. Bethesda (MD): National Institutes of Health, National Institute of Diabetes and Digestive and Kidney Diseases; 2006.

8. Sarnak MJ, Levey AS, Schoolwerth AC, Coresh J, Culleton B, Hamm LL, et al. Kidney disease as a risk factor for development of cardiovascular disease: a statement from the American Heart Association Councils on Kidney in Cardiovascular Disease, High Blood Pressure Research, Clinical Cardiology, and Epidemiology and Prevention. Circulation. 2003;108:2154-69.

9. Liu JY, Birkmeyer NJ, Sanders JH, Morton JR, Henriques HF, Lahey SJ, et al. Risks of morbidity and mortality in dialysis patients undergoing coronary artery bypass surgery. Northern New England Cardiovascular Disease Study Group. Circulation. 2000;102:2973-7.

10. Ferguson TB Jr, Hammill BG, Peterson ED, DeLong ER, Grover FL. A decade of change-risk profiles and outcomes for isolated coronary artery bypass grafting procedures, 1990-1999: a report from the STS National Database Committee and the Duke Clinical Research Institute. Society of Thoracic Surgeons. Ann Thorac Surg. 2002;73: 480-90.

11. Zimmet AD, Almeida A, Goldstein J, Shardey GC, Pick AW, Lowe CE, et al. The outcome of cardiac surgery in dialysis-dependent patients. Heart Lung Circ. 2005; 14:187-90.

12. Horst M, Mehlhorn U, Hoerstrup SP, Suedkamp M, de Vivie ER. Cardiac surgery in patients with end-stage renal disease: 10 -year experience. Ann Thorac Surg. 2000;69:96-101.

13. Hassler R, Hofling B, Castro L, Gurland HJ, Hillebrand G, Land W, et al. [Coronary heart disease and heart valve diseases in patients with terminal kidney insufficiency]. Dtsch Med Wochenschr (1946) 1987; 112:714-8.

14. Charytan DM, Kuntz RE. Risks of coronary artery bypass surgery in dialysis-dependent patients-analysis of the 2001 National Inpatient Sample. Nephrol Dial Transplant. 2007;22:1665-71.

15. The Parisian Mediastinitis Study Group. Risk factors for deep sternal wound infection after sternotomy: a prospective, multicenter study. J Thorac Cardiovasc Surg. 1996;111:1200-7.

16. John R, Choudhri AF, Weinberg AD, Ting W, Rose EA, Smith CR, et al. Multicenter review of preoperative risk factors for stroke after coronary artery bypass grafting. Ann Thorac Surg. 2000;69:30-6.

17. Filsoufi F, Rahmanian PB, Castillo JG, Scurlock C, Legnani PE, Adams DH. Predictors and outcome of gastrointestinal complications in patients undergoing cardiac surgery. Ann Surg. 2007;246: 323-9.

18. Yellin A, Refaely Y, Paley M, Simansky D. Major bleeding complicating deep sternal infection after cardiac surgery. $J$ Thorac Cardiovasc Surg. 2003;125:554-8.

19. Franga DL, Kratz JM, Crumbley AJ, Zellner JL, Stroud MR, Crawford FA. Early and long-term results of coronary artery bypass grafting in dialysis patients. Ann Thorac Surg. 2000;70:813-9.

20. Jault F, Rama A, Bonnet N, Reagan M, Nectoux M, Petitclerc T, et al. Cardiac surgery in patients receiving long term hemodialysis. Short and long term results. J Cardiovasc Surg. 2003;44:725-30. 


\section{Appendix 1. Variables included in this study}

\section{Variables}

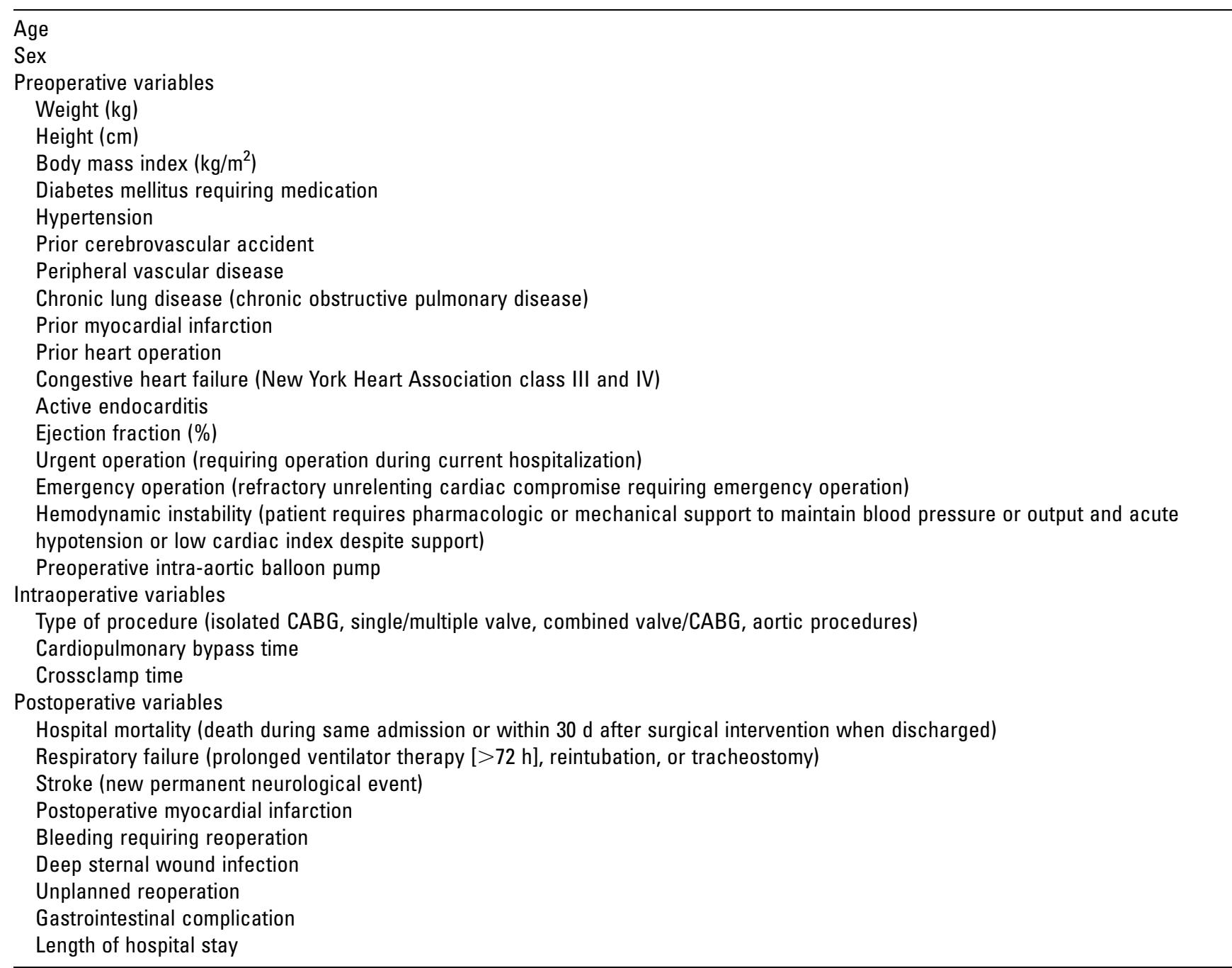

$C A B G$, Coronary artery bypass grafting. 